\title{
DIREITO CIVIL-CONSTITUCIONAL E OS DIREITOS FUNDAMENTAIS NO ÂMBITO DAS RELAÇÕES ENTRE PARTICULARES
}

\section{CIVIL-CONSTITUTIONAL LAW AND THE FUNDAMENTAL RIGHTS WITHIN THE RELATIONS BETWEEN PARTIES}

\author{
Cleyson de Moraes Mello*
}

Nuno Manuel Morgadinho dos Santos Coelho**

Resumo: A aplicação dos Direitos Fundamentais nas relações entre privados tem ganhado espaço e reconhecimento nas decisões do Judiciário e na doutrina. Este estudo buscará por meio de revisão bibliográfica analisar tal possibilidade

Palavras-Chave: Direitos Fundamentais; Relações Privadas; Constituição.

Abstract: The application of the Fundamental Rights in the relationships among private has been winning space and recognition in the decisions of the Judiciary and in the Doctrine. This study will go through a bibliographical revision to analyze such possibility. Keywords: Fundamental Rights; Private Relationships; Constitution.

\section{INTRODUÇÃO}

Não é possível pensar o direito sem pensar em sua essência

a. Da mesma forma que hoje não é possível pensar em direito civil sem pensar em direito civil-constitucional. Pensar em direito civil-constitucional é, pois, pensar a essência da "personalidade", ou seja, a tutela da pessoa humana como centro irradiador existencial das relações jurídicas interprivadas. A personalidade é a vivência que está no núcleo da dogmática jurídica civilística. É o novo elemento que iremos encontrar a partir de uma (re)leitura do Código Civil com as lentes voltadas para a tábua axiológica constitucional. Os princípios e valores constitucionais ganham proeminência no processo de interpretação e aplicação do Direito.

Todavia, Renan Lotufo lembra, fazendo justiça à genialidade de Clóvis Beviláqua, que "Clóvis foi o precursor do Direito Civil-Constitucional, ao tratar do tema sob a denominação 'A Constituição e o Código Civil', onde inovadoramente refere à Constituição de 1934, e suas repercussões sobre dispositivos do Código Civil”, publicada na RT 97, de setembro de 1935 , às páginas 31 a $38 .^{1}$

\footnotetext{
* Professor do curso de Direito da UERJ. E-mail: profcleysonmello@ hotmail.com

** Professor do curso de Direito da USP e UNAERP. E-mail: nunommcoelho@yahoo.com
} 
Com o advento do Código Civil brasileiro de 2002 ganham destaque às cláusulas gerais e os direitos da personalidade. As cláusulas gerais devem ser interpretadas em harmonia com os princípios fundantes da Constituição da República, já que o intérprete jurídico deve colorir a exegese civilística com os matizes axiológicos da principiologia constitucional. Nesse momento, os valores civilísticos de índole liberal devem ser mitigados pelos valores coletivos de solidariedade e justiça social.

É, pois, uma nova essência contida na exegese das relações jurídicas interprivadas. Referimo-nos à chamada alteridade ou alteritas. É um agir pensando no outro, isto é, o "eu" reclama um agir pressupondo o "outro"; o ego, o alter. Não podemos pensar o “eu”, sem nesse pensar ir já envolto o “outro". Esta alteridade é, pois, da essência do direito civil-constitucional. Desde Tomás de Aquino (1225 - 1274) até os recentes estudos do Existencialismo, a alteridade esteve e está presente. O eu e o outro são como os dois polos da relação jurídica, sempre plural, nunca singular. Ora é aqui que justamente se nos impõe a ideia de superação do individualismo de índole liberal, já que as relações jurídicas se aproximam mais à ideia de colaboração, convivência, mundo vivido, solidariedade e justiça social. É, pois, a essência da alteridade que se desvela ao mundo jurídico.

Estes elementos não podem ser pensados como grandezas estáticas, abstratas, formais. É uma ideia de relação jurídica interprivada que se equivale a uma coexistência, ou um existir lado-a-lado que se impõe em sua dinamicidade do mundo vivido. São grandezas dinâmicas de um movimento próprio a que podemos chamar de "ontológico".

Na esteira da filosofia de Heidegger, Sartre, Jaspers, a personalidade humana deve ganhar status de valor jurídico de cunho existencialista, já que esta não pode ficar aprisionada ao rol de direitos subjetivos típicos adotado pelo Código Civil. Daí a importância do entrelaçamento principiológico entre o direito civil e os direitos humanos.

É não menos que (re)visitar os institutos jurídicos do direito civil a partir de uma hermenêutica plural individualizadora cunhada por uma essencial unidade socializadora, a partir da qual a relação jurídica de direito privado é vista como uns e muitos, como eu e outro, como uma relação jurídica irremediavelmente lastreada pelos princípios fundamentais de proteção da dignidade da pessoa humana (art. $1^{\circ}$, III, CRFB/88), solidariedade social (art. $3^{\circ}$, I, CRFB/88), valor social da livre iniciativa (art. $1^{\circ}, \mathrm{IV}, \mathrm{CRFB} / 88$ ) e igualdade substancial (art. $3^{\circ}$, III, CRFB/88). É, pois, uma essênciarelacional de cariz civil-constitucional. 
Assim, qualquer pessoa que tenha na cabeça todos os artigos do Código Civil não será um cientista jurídico e sequer um bom operador do direito. Conhecer o Código Civil somente não basta, já que lhe faltariam os conhecimentos essenciais de hermenêutica jurídica e filosófica, bem como os alicerces do direito civil-constitucional.

Antes mesmo do advento do novo Código Civil de 2002, Francisco Amaral já alertava sobre as tendências do direito civil contemporâneo, a saber: ${ }^{2}$

I) Interpenetração crescente do direito civil com o constitucional e a consequente superação da clássica dicotomia direito público - direito privado;

II) Personalização do direito civil, no sentido da crescente importância da vida e da dignidade da pessoa humana, elevadas à categoria de direitos e de princípio fundamental da Constituição. É o personalismo ético da época contemporânea;

III) Desagregação do direito civil, face ao surgimento de ramos jurídicos autônomos, que se formam devido à complexidade das relações jurídicas. Por exemplo, direito imobiliário, direito bancário, direito previdenciário, etc.

IV) Reservas à Codificação. O Código Civil deixa de ser o "estatuto orgânico da vida privada", em virtude da necessidade da releitura do Código Civil à luz dos princípios constitucionais;

V) Surgimento dos microssistemas jurídicos. É a chamada "Era dos Estatutos" que surgem para disciplinar temas específicos.

\section{ENTRE O PÚBLICO E O PRIVADO}

A personalidade jurídica não pode ser considerada somente como a aptidão de ser titular de direitos e deveres, conforme prescreve o artigo $1^{\circ}$ do Código Civil, ou seja, considerada como sinônimo de capacidade jurídica. Ao contrário, a compreensão da personalidade jurídica deve se dar em duas vertentes: a primeira, como a possibilidade de ser sujeito de direitos e deveres e a segunda, e mais relevante, como o sentido existencial do próprio ser humano, visto como valor fundamental de nosso ordenamento jurídico. Neste caso, é o princípio da dignidade da pessoa humana ressoando em sua mais nobre originalidade.

Nesse caso, frise-se, mais uma vez, a importância dos estudos avançados de hermenêutica jurídica e direito civil-constitucional, uma vez que aquela deixa de ser considerada como hermenêutica de orientação metodológico-científica (modo de conhecer) para ser estudada como hermenêutica ontológica (modo de ser).

R. Fac. Dir. UFG, v. 40, n.2, p. 134-150, jul. / dez. 2016

ISSN 0101-7187 
Direito Civil-Constitucional e os Direitos Fundamentais no Âmbito das Relações [...]

A clássica dicotomia direito público - direito privado não representa nos dias atuais esferas distintas de atuação do intérprete jurídico, pelo contrário, constituem um conteúdo nuclear comum que representa a incidência de vetores axiológicos constitucionais no direito privado. Este fenômeno é chamado de "constitucionalização do direito civil" ou "civilização do direito constitucional".

Este núcleo comum constituído pelo entrelaçamento das normas do direito público e do direito privado refere-se à incidência da principiologia constitucional no âmbito do direito civil, especialmente, no que versa sobre direitos da personalidade, direito de família, direito de propriedade ${ }^{3}$ e relações negociais, razão pela qual o direito civil deve ser estudado à luz dos paradigmas constitucionais com o firme propósito de construir-se uma sociedade justa e solidária.

Na sua peculiar lucidez, Gustavo Tepedino aponta que o direito público e o direito privado constituíram, para a cultura jurídica dominante na Escola da Exegese, "dois ramos estanques e rigidamente compartimentados. Para o direito civil, os princípios constitucionais equivaleriam a normas políticas, destinadas ao legislador e, apenas excepcionalmente, ao intérprete, que delas poderia timidamente se utilizar, nos termos do art. $4^{\circ}$ da Lei de Introdução ao Código Civil, como meio de confirmação ou de legitimação de um princípio geral de direito". ${ }^{4}$ Daí que, ainda hoje, muitos operadores do direito aplicam a legislação ordinária civilista no âmbito das relações de direito privado, desatentos às normas e princípios constitucionais.

A cultura jurídica operada em salas de aula e nos tribunais de justiça deve ser desconstruída (visão de um sistema fechado codicista) em busca de uma postura metodológica mais aberta, prospectiva que dê suporte a uma sociedade complexa e pluralista. Isso não quer dizer que o julgador desconsidere a segurança jurídica e passe a decidir de forma arbitrária (neste caso, estaríamos diante de um Estado-Judiciário). Pelo contrário, a jurisprudência deve reconhecer a eficácia normativa dos princípios constitucionais no âmbito das relações jurídicas de direito privado, bem como recorrer à hermenêutica jurídica não como um conjunto de metódos (hermenêutica metodológica), mas sim como condição de possibilidade (hermenêutica filosófica). É a reconstrução do direito civil a partir do como hermenêutico, ou seja, um locus hermenêutico constitucional com fincas no princípio fundante da proteção da dignidade da pessoa humana. ${ }^{5}$

A propósito, Gustavo Tepedino ensina que "a inclusão dos institutos de direito civil, como contrato, propriedade e família, na agenda atinente à ordem pública R. Fac. Dir. UFG, v. 40, n.2, p. 134-150, jul. / dez. 2016 
associa-se à irradiação dos princípios constitucionais nos espaços de liberdade individual. Com efeito, a partir da interferência da Constituição no âmbito antes reservado à autonomia privada, uma nova ordem pública há de ser construída, coerente com os fundamentos e objetivos fundamentais da República". ${ }^{6}$

Da mesma forma, Daniel Sarmento trata da eficácia irradiante dos direitos fundamentais ao afirmar que "esta significa que os valores que dão lastro aos direitos fundamentais penetram por todo o ordenamento jurídico, condicionando a interpretação das normas legais e atuando como impulsos e diretrizes para o legislador, a administração e o Judiciário. A eficácia irradiante, neste sentido, enseja a "humanização" da ordem jurídica, ao exigir que todas as suas normas sejam, no momento de aplicação, reexaminadas pelo operador do direito com novas lentes, que terão as cores da dignidade humana, da igualdade substantiva e da justiça social, impressas no tecido constitucional". 7

Ora perguntar-se-á agora: a irradiação dos princípios constitucionais nas relações jurídicas interprivadas é apenas um movimento de construção científica que fomenta os estudos avançados de direito civil?

Bastar-nos-á talvez trazer exemplos sobre a realidade mais concreta dos fatos e dados da experiência jurídica. A respeito dessas realidades, Tepedino anota que “exemplos não faltam dessa mudança qualitativa da autonomia privada e da insuficiência das categorias tradicionalmente consagradas na dogmática do direito civil para solucionar os novos conflitos de interesse. O Professor Stefano Rodotà, em uma das três conferências que ministrou no Rio de Janeiro, a convite da Universidade do Estado do Rio de Janeiro e da Procuradoria do Município da Cidade do Rio de Janeiro, invocou a notícia publicada por um tabloide sensacionalista inglês, que pôs em dúvida a paternidade do príncipe William. Insinuou-se então que o herdeiro real poderia ser filho não de Charles, mas de um exprofessor de educação física da princesa Diana. O repórter, aproveitando-se de um descuido do jovem príncipe, acometido de uma gripe, apropriou-se de um lenço de papel por ele utilizado e jogado em uma lata do lixo. Valendo-se também de uma amostra do sangue (ou tecido) do pretenso pai, realizou o confronto das cadeias de DNA, cujo resultado negativo estancou a explosão nas vendas dos jornais populares e a apreensão geral relacionada à sucessão do trono. O Professor Rodotà, analisando a questão, esclareceu apropriadamente que não se tratava apenas de um lenço descartado (res derelectae), mas de informações que diziam respeito à própria essência da personalidade daqueles de quem foram apropriados. 
Por isso mesmo, a circulação e utilização dos chamados dados sensíveis devem depender de manifestação expressa daqueles que terão aspectos de sua intimidade revelados". 8

É, pois, preciso (re)conduzir o direito, em especial, o direito civil a sua existência e essência, já este não pode ficar atento apenas ao fato jurídico (factum), mas no "fazendo-se" constante (faciendum), inobjetificáveis e anticonceituais. $O$ direito civil é produto da vida privada como existência e convivência. A ontologia existencial (re)direciona o homem como existência concreta, ao realizar-se temporalizando-se, já que Ser é Tempo. Aqui, o tempo se identifica com a existência.

Na obra Hermenêutica e direito, ${ }^{9}$ antes de tudo, procuramos fundamentar o direito na Ontologia fundamental de Heidegger e, em seguida, na hermenêutica filosófica de Hans-Georg Gadamer. O estudo é guiado pela fenomenologia hermenêutica e procura investigar o sentido do ser, através das estruturas do ser-aí pautado nos teoremas da diferença ontológica (analítica existencial) e do círculo hermenêutico. Ao final, apresentamos considerações e sugestões, tendo em vista que a hermenêutica alimentada pela ontologia fundamental torna possível compreender-nos como ser-no-mundo a partir de e na estrutura prévia de sentido. É assim que se entende que a compreensão do Direito é a forma originária de realização da pre-sença (Dasein, ser-aí), que é ser-no-mundo; o conceito de ser-no-mundo como locus de justificação para as proposições científicas e filosóficas.

\section{DIREITOS FUNDAMENTAIS}

O termo "direitos fundamentais" é encontrado na dogmática jurídica em várias expressões, tais como: "direitos humanos", "direitos do homem", "direitos subjetivos públicos", "liberdades públicas", "direitos individuais", "liberdades fundamentais" e "direitos humanos fundamentais". ${ }^{10}$

No próprio texto constitucional, a expressão direitos fundamentais se apresenta de forma diversificada, tais como: a) direitos humanos (art. $4^{\circ}$, II, da $\mathrm{CRFB} / 88$ ); b) direitos e garantias fundamentais (Título II e art. $5^{\circ}, \S 1^{\circ}$, da CRFB/88); c) direitos e liberdades constitucionais (art. 5\%, LXXI, da CRFB/88) e d) direitos e garantias constitucionais (art. 60, $\S 4^{\circ}, \mathrm{IV}$, da CRFB/88).

A compreensão dos direitos fundamentais é vital para a superação do direito positivo, já que pretende aproximá-lo da filosofia do direito. É uma espécie de R. Fac. Dir. UFG, v. 40, n.2, p. 134-150, jul. / dez. 2016 
aproximação do direito com a moral. Daí a importância do estudo do direito civil em harmonia com os direitos fundamentais, na busca de uma fundamentação constitucional para as decisões dos casos concretos na esfera interprivada.

Gregorio Peces-Barba Martínez ensina que "en los derechos fundamentales el espíritu y la fueza, la moral y el Derecho están entrelazados y la separación los mutila, los hace incomprensibles. Los derechos fundamentales son una forma de integrar justicia y fuerza desde la perspectiva del individuo propio de la cultura antropocéntrica del mundo moderno". 11

\section{A CONCEPÇÃO DOS DIREITOS FUNDAMENTAIS NA CONSTITUIÇÃO DE 1988}

O Título II (Dos Direitos e Garantias Fundamentais) da Constituição da República Federativa do Brasil de 1988 apresenta um rol extenso de direitos fundamentais. Somente o artigo $5^{\circ}$ constitucional contempla 77 incisos. ${ }^{12}$ Já o artigo $7^{\circ}$, com seus 34 incisos, apresenta um vasto rol de direitos sociais dos trabalhadores.

O catálogo dos direitos fundamentais consagrados na Constituição abarca vários direitos em suas variadas dimensões: direito à vida, à liberdade, à propriedade, direitos sociais básicos, direito ao meio ambiente ecologicamente equilibrado (art. 225, da $\mathrm{CRFB} / 88$ ), proteção ao consumidor, dentre outros.

Os direitos fundamentais podem ser classificados, de acordo com sua multifuncionalidade, em dois grandes grupos, a saber: ${ }^{13}$

a) direitos de defesa, aí incluídos os direitos de liberdade, igualdade, as garantias, bem como parte dos direitos sociais (liberdades sociais) e políticos. São direitos que impõem uma abstenção por parte do Estado e, em regra, representam os direitos subjetivos;

b) direitos a prestações integrados pelos direitos a prestações em sentido amplo, tais como os direitos à proteção e à participação na organização e procedimento, assim como pelos direitos a prestações em sentido estrito, representados pelos direitos sociais de natureza prestacional.

É necessário lembrar a cláusula de abertura prevista pelo art. $5^{\circ}, \S 2^{\circ}$, da Constituição. Nesse sentido cumpre referir que o "conceito materialmente aberto dos direitos fundamentais consagrado pelo art. $5^{\circ}, \S 2^{\circ}$, da $\mathrm{CF}$ aponta para a existência de 
Direito Civil-Constitucional e os Direitos Fundamentais no Âmbito das Relações [...]

direitos fundamentais positivados em outras partes do texto constitucional e até mesmo em tratados internacionais, bem assim para a previsão expressa da possibilidade de se reconhecer direitos fundamentais não-escritos, implícitos nas normas do catálogo, bem como decorrentes do regime e dos princípios da Constituição". ${ }^{14}$

Vale destacar que o catálogo dos direitos fundamentais constitui em si uma concretização do princípio fundamental da dignidade da pessoa humana ( $\operatorname{art} .1^{\circ}$, inciso III, da CRFB/88). Daí que o princípio da dignidade humana constitui um locus hermenêutico aberto que deve ser harmonizado com a diversidade de valores que se manifestam nas sociedades complexas e plurais. É a questão da intersubtividade e alteridade da norma jurídica, já que a dimensão intersubjetiva da dignidade humana deve ser compreendida a partir da relação do ser humano com os demais membros da sociedade em que vive.

\section{A DIFERENÇA ENTRE DIREITOS FUNDAMENTAIS E DIREITOS HUMANOS}

Segundo Ingo Wolfgang Sarlet a distinção é de que o termo direitos fundamentais "se aplica para aqueles direitos do ser humano reconhecidos e positivados na esfera do direito constitucional positivo de determinado Estado, ao passo que a expressão "direitos humanos" guardaria relação com os documentos de direito internacional, por referir-se àquelas posições jurídicas que se reconhecem ao ser humano como tal, independentemente de sua vinculação com determinada ordem constitucional, e que, portanto, aspiram à validade universal, para todos os povos e tempos, de tal sorte que revelam um inequívoco caráter supranacional (internacional)". ${ }^{15}$

Dessa maneira, os direitos fundamentais representam os direitos

reconhecidos pelo ordenamento constitucional interno de cada Estado e os direitos humanos são aqueles reconhecidos pelo direito internacional com validade universal e de contornos mais amplos e imprecisos.

Da mesma forma, as lições de Antonio-Enrique Pérez Luño, "Los derechos humanos suelen venir entendidos como un conjunto de facultades e instituciones que, en cada momento histórico, concretan las exigencias de la dignidad, la libertad y la igualdad humanas, las cuales deben ser reconocidas positivamente por los ordenamientos jurídicos a nivel nacional e internacional. En tanto que con la noción de los derechos fundamentales R. Fac. Dir. UFG, v. 40, n.2, p. 134-150, jul. / dez. 2016 
se tiende a aludir a aquellos derechos humanos garantizados por el ordenamiento jurídico positivo, en la mayor parte de los casos en su normativa constitucional, y que suelen gozar de una tutela reforzada". ${ }^{16}$

\section{AS DIMENSÕES DOS DIREITOS FUNDAMENTAIS}

O processo de reconhecimento dos direitos fundamentais no âmbito do direito positivo dá margem a sua compreensão a partir das características de seu conteúdo. Tais características podem ser agrupadas em dimensões (gerações):

a) Direitos fundamentais da primeira geração: São aqueles de índole liberal-individualista, fruto do pensamento liberal-burguês do século XVIII, que representam os direitos individuais frente ao Estado. Os direitos fundamentais de primeira geração estão relacionados aos direitos de cunho jusnaturalista, tais como: os direitos à vida, à liberdade, à propriedade, à igualdade (igualdade formal) perante a lei. Nesta dimensão estão incluídos, também, os direitos de participação política e as liberdades de expressão coletiva (liberdades de expressão, imprensa, manifestação, reunião, associação, etc.)

b) Direitos fundamentais da segunda geração: Os direitos fundamentais da segunda geração estão relacionados aos direitos econômicos, sociais e culturais. Como observa Ingo Sarlet, estes direitos "não englobam apenas direitos de cunho positivo, mas também as assim denominadas 'liberdades sociais', do que dão conta os exemplos da liberdade de sindicalização, do direito de greve, bem como do reconhecimento de direitos fundamentais aos trabalhadores, tais como o direito a férias e ao repouso semanal remunerado, a garantia de um salário mínimo, a limitação da jornada de trabalho". ${ }^{17}$

c) Direitos fundamentais da terceira geração: Os direitos fundamentais da terceira geração são aqueles denominados de direitos de solidariedade. São caracterizados pelos direitos transindividuais, também chamados direitos coletivos e difusos e que, no geral, compreendem os direitos do consumidor e dos direitos relacionados à proteção do meio ambiente, respectivamente.

d) Direitos fundamentais da quarta geração: Os direitos fundamentais da quarta geração são os direitos de manipulação genética, relacionados à biotecnologia e bioengenharia, e que tratam de questões sobre a vida e a morte, sobre cópias de seres humanos, e que requerem uma discussão ética prévia; e

e) Direitos fundamentais da quinta geração: Os direitos fundamentais da quinta geração estão relacionados aos direitos da realidade virtual, que surgem do grande desenvolvimento da cibernética. 


\section{A EFICÁCIA DOS DIREITOS FUNDAMENTAIS}

A eficácia dos direitos fundamentais está relacionada com a força normativa dos preceitos constitucionais. $\mathrm{O}$ artigo $5^{\circ}, \S 1^{\circ}$, da Constituição da República Federativa do Brasil de 1988 determina que "as normas definidoras dos direitos e garantias fundamentais têm aplicação imediata". Além da clássica distinção entre as normas autoaplicáveis (selfexecuting, self-acting, ou self-enforcing) e normas não-autoaplicáveis (not self-executing, not self-acting, ou not self-enforcing) e das diversas concepções doutrinárias existentes, José Afonso da Silva apresenta uma teoria tricotômica das normas constitucionais, discriminando-as em três categorias: ${ }^{18}$

I - normas constitucionais de eficácia plena - São as normas que, dotadas de aplicabilidade direta, imediata e integral, não dependem da atuação do legislador ordinário para que alcancem sua plena operatividade;

II - normas constitucionais de eficácia contida - São normas constitucionais de aplicabilidade direta e imediata, mas possivelmente não-integral. Algumas normas desse tipo indicam "elementos de sua restrição que não a lei, mas certos conceitos de larga difusão no direito público, tais como ordem pública, segurança nacional ou pública, integridade nacional, bons costumes, necessidade ou utilidade pública, perigo público iminente, etc".; ${ }^{19}$

III - normas constitucionais de eficácia limitada ou reduzida. São normas de aplicabilidade indireta e reduzida, já que necessário se faz a intervenção legislativa ordinária para a produção de seus efeitos jurídicos. Estas normas podem ser subdivididas em normas declaratórias de princípios institutivos ou organizativos e normas declaratórias de princípio programático.

Já Maria Helena Diniz classifica as normas constitucionais quanto ao seu efeito, em 4 grupos, a saber: ${ }^{20}$

a) Normas com eficácia absoluta - São normas intangíveis e insuscetíveis de alteração, até mesmo por Emenda Constitucional. São normas que independem da atuação do legislador ordinária para geração de efeitos;

b) Normas com eficácia plena - São normas que independem da atuação do legislador ordinária para geração de efeitos, criando desde logo direitos subjetivos. Todavia, são suscetíveis de alteração através de emenda constitucional;

c) Normas com eficácia relativa restringível - Apresentam aplicabilidade direta e imediata, gerando os efeitos jurídicos nela previstos. Estas normas estão sujeitas a restrições previstas na legislação ordinária ou podem depender de regulamentação posterior, reduzindo a sua aplicabilidade, e 
d) Normas com eficácia relativa complementável ou dependente de complementação legislativa, de aplicação apenas mediata (indireta) - São aquelas que não geram efeitos jurídicos desde logo, abrangendo as normas de princípios institutivos e as normas programáticas.

Além das classificações anteriores, Luís Roberto Barroso apresenta a seguinte tipologia das normas constitucionais: ${ }^{21}$

a) Normas constitucionais de organização - São normas que têm por objeto organizar o exercício do poder político;

b) Normas constitucionais definidoras de direitos - São as normas que devem fixar os direitos fundamentais dos indivíduos, e

c) Normas constitucionais programáticas - São as normas constitucionais que procuram traçar os fins públicos a serem alcançados pelo Estado.

As diversas concepções e distinções das normas jurídicas constitucionais sob o aspecto da aptidão de geração de efeitos (eficácia jurídica) são fruto do entendimento doutrinário de que inexiste norma constitucional completamente destituída de eficácia. Daí a importância da análise e estudo da graduação da carga eficacial das normas jurídicas.

Para Ingo Wolfgang Sarlet, em todas as classificações se destacam dois grupos de normas: ${ }^{22}$

a) as normas que dependem, para a geração de seus efeitos principais, da intervenção do legislador infraconstitucional (normas constitucionais de baixa densidade normativa) e

b) as normas que, desde logo, por apresentarem suficiente normatividade, estão aptas a gerar seus efeitos e, portanto, dispensam uma interpositio legislatoris (normas constitucionais de alta densidade normativa).

Sarlet prefere acompanhar a sistematização binária da norma jurídica, distinguindo entre as normas de eficácia plena e as normas de eficácia limitada ou reduzida. Vale lembrar que até mesmo as normas constitucionais de baixa densidade normativa apresentam uma normatividade mínima, já que sempre apresentam certo grau de eficácia jurídica. ${ }^{23}$

Dessa forma, levando em consideração a distinção sistemática das normas constitucionais, bem como o teor da norma contida no artigo $5^{\circ}, \S 1^{\circ}$, da Constituição da República Federativa do Brasil de 1988, a melhor exegese deste dispositivo constitucional é no sentido de que ele apresenta um viés principiológico. Melhor dizendo: $\mathrm{O}$ artigo $5^{\circ}, \S$ $1^{\text {o }}$, de nossa Constituição representa uma espécie de "mandado de otimização (ou 
Direito Civil-Constitucional e os Direitos Fundamentais no Âmbito das Relações [...]

maximização), isto é, estabelecendo aos órgãos estatais a tarefa de reconhecerem a maior eficácia possível aos direitos fundamentais". ${ }^{24}$

A partir da exegese do artigo $5^{\circ}, \S 1^{\circ}$, da CRFB/88, podemos entender que os direitos fundamentais possuem aplicabilidade imediata e plenitude eficacial, bem como incumbe aos poderes públicos atribuir a estas maior eficácia possível (postulado otimizador).

\section{DIREITOS FUNDAMENTAIS NO ÂMBITO DAS RELAÇÕES ENTRE PARTICULARES}

Nos últimos anos, a questão do direito civil-constitucional está em voga, ou seja, discute-se a influência do direito constitucional na esfera jurídica civilística, onde se indaga o papel dos princípios e regras constitucionais aplicado às normas infraconstitucionais. É o fenômeno denominado de "constitucionalização do direito civil".

A dogmática e a codificação civilista não pode ser interpretada dissociada dos valores e princípios constitucionais. Daí a importância, cada vez maior, do estudo do direito civil em harmonia e consonância com a normativa constitucional.

Nesses termos, um pensamento originário começa a fluir no campo jurídico civilístico. Esse caminhar foi guiado não só pela filosofia constitucional, bem como por estudiosos do vigor de Luiz Edson Fachin, Francisco Amaral, Gustavo Tepedino, Maria Celina Bodin de Moraes, Teresa Negreiros, Judith Martins-Costa, Daniel Sarmento, dentre outros, que já trilharam caminhos inesperados sempre adornados com novas cores. São estes autores que estão dispostos a conhecer e a buscar a essência do direito civil, em seu sentido originário.

Daí a necessidade de apresentar, de forma preliminar, no Curso de direito civil, a problemática da eficácia das normas de direitos fundamentais no âmbito das relações interprivadas. É um tema que se discute desde a década de 50 do século passado, em especial, na Alemanha sob a denominação de "efeito frente a terceiros dos direitos fundamentais" (Drittwirkung der Grundrechte). De igual forma, nos Estados Unidos o assunto é chamado de state action doctrine. 
As teses ou orientações doutrinárias quanto à eficácia dos direitos fundamentais relativamente a terceiros podem ser agrupadas em: a) a tese de recusa de eficácia; b) a tese da eficácia mediata ou indireta; c) as teses dos deveres de proteção; d) a tese da eficácia direta ou imediata. ${ }^{25}$

Se por um lado devemos refletir sobre a eficácia dos direitos fundamentais na ordem jurídica civilística, por outro, devemos ficar atentos a essa influência, para não transformar o direito civil em um direito de "não-liberdade", já que a gênese do direito privado é a liberdade e autonomia das partes.

Em nome da autonomia da vontade e da liberdade contratual seria possível admitir a violação da dignidade da pessoa humana quando ameaçada por outros particulares? Jorge Reis Novais admite que dessa maneira seria "fazer prevalecer os direitos patrimoniais e o direito de propriedade sobre os direitos de liberdade pessoais, seria sacrificar os direitos fundamentais no altar de uma sacralização da livre iniciativa privada numa hierarquização de prioridades que, objetivamente, oculta o domínio dos economicamente mais poderosos". ${ }^{26}$

Aqui a divergência doutrinária resplandece. Vejamos as lições de Novais: "Por isso, diz-se, quem é mais pelos direitos fundamentais favorece a tese da aplicabilidade direta, quem é mais pela autonomia privada sustentará as outras teses. Quem é pela intervenção estatal de correção das assimetrias sociais e de limitação dos poderes privados, quem tem preocupações igualitárias, sustentará a aplicabilidade geral dos direitos fundamentais, incluindo às relações econômicas e sociais privadas; quem tem uma maior preocupação com a conservação de um status inigualitário favorecerá o acantonamento dos direitos fundamentais nas relações com o Estado, preservando a esfera privada das perturbações implicadas numa generalização indiscriminada dos destinatários dos direitos fundamentais". 27

$\mathrm{Na}$ atualidade não se pode afirmar que os direitos fundamentais devam ser exercidos somente contra o Estado, deixando a liberdade contratual e a autonomia da vontade livres da interferência do Estado, a serem conduzidas somente pelos particulares.

$\mathrm{Na}$ aplicação dos direitos fundamentais nas relações entre particulares ocorrerá uma colidência ou conflito de um direito fundamental e o princípio da autonomia privada que também representa uma garantia jurídico-constitucional.

Contudo, o tema não é apresentado e discutido nos manuais de direito civil, razão pela qual a problemática somente é enfrentada em sede de pós-graduação em direito. Como tantos outros temas, tornou-se necessário enfrentar a questão da 
Direito Civil-Constitucional e os Direitos Fundamentais no Âmbito das Relações [...] incidência dos direitos fundamentais e sua eficácia no âmbito das relações jusprivatística. Não obstante a controvérsia que permeia a dogmática jurídica constitucional, entende-se que os direitos fundamentais se projetam sobre as relações interprivadas de forma a conformá-las sob o manto constitucional. Daí a importância da interpretação do Código Civil à luz dos cânones e princípios constitucionais. Nesse contexto, Tepedino ensina que "propriedade, empresa, família, relações contratuais tornam-se institutos funcionalizados à realização dos valores constitucionais, em especial da dignidade da pessoa humana, não mais havendo setores imunes a tal incidência axiológica, espécies de zonas francas para atuação da autonomia privada. A autonomia privada deixa de configurar um valor em si mesma, e será merecedora de tutela somente se representar, em concreto, a realização de um valor constitucional".28

Dessa maneira, as relações jurídicas privadas devem ser conformadas pelos princípios jurídicos constitucionais, tais como, o princípio da dignidade da pessoa humana (CRFB/88, art. $1^{\circ}$, III), e os princípios do trabalho e da livre iniciativa como valores sociais (CRFB/88, art. $\left.1^{\circ}, \mathrm{IV}\right)$, com vistas a construir uma sociedade livre, justa e solidária (CRFB/88, art. 3º $\mathrm{I})$, a garantir o desenvolvimento nacional (CRFB/88, art. $3^{\circ}$, II), erradicar a pobreza e a marginalização e reduzir as desigualdades sociais e regionais (CRFB/88, art. $3^{\circ}$, III), bem como promover o bem de todos, sem preconceitos de origem, raça, sexo, cor, idade e quaisquer outras formas de discriminação (CRFB/88, art. $3^{\circ}$, IV).

Não obstante a nossa Constituição da República Federativa do Brasil de 1988 não apresentar explicitamente o mandamento da eficácia dos direitos fundamentais a ordem jurídica privada, estes devem possuir eficácia tanto no plano das relações verticais (relações entre indivíduo e Estado) como nas relações horizontais (relações entre particular e particular), com o firme propósito de perseguir uma sociedade livre, justa e solidária.

\section{REFERÊNCIAS}

AMARAL, Francisco. Direito civil: introdução. 3. ed. Rio de Janeiro: Renovar, 2000.

BARROSO, Luís Roberto. O direito constitucional e a efetividade de suas normas. 5. ed. Rio de Janeiro: Renovar, 2001. 
DINIZ, Maria Helena. Norma constitucional e seus efeitos. 6. ed. São Paulo: Saraiva, 2003.

LOTUFO, Renan. Da oportunidade da codificação civil e a constituição. In: SARLET, Ingo Wolfgang (Org.) O novo código civil e a constituição. 2. ed. Porto Alegre: Livraria do Advogado, 2006.

MARTÍNEZ, Gregorio Peces-Barba. Lecciones de derechos fundamentales. Madrid: Dykinson, 2004.

MELLO, Cleyson de Moraes. Hermenêutica e direito. Rio de Janeiro: Freitas Bastos, 2006.

. Código civil interpretado. Rio de Janeiro: Freitas Bastos, 2007.

NOVAIS, Jorge Reis. Direitos fundamentais: trunfos contra a maioria. Coimbra: Coimbra Editora, 2006.

PEREZ LUÑO, Antonio-Enrique. Los derechos fundamentales. 8. ed. Madrid: Tecnos, 2004.

TEPEDINO, Gustavo. O código civil, os chamados microssistemas e a constituição: premissas para uma reforma legislativa. In: TEPEDINO, Gustavo (Org.) Problemas de direito civil. Rio de Janeiro: Renovar, 2000.

Normas constitucionais e direito civil na construção unitária do ordenamento. In:

SOUZA NETO; Cláudio Pereira de; SARMENTO, Daniel. (Orgs.) A constitucionalização do direito: fundamentos teóricos e aplicações específicas. Rio de Janeiro. Lumen Juris, Renovar. 2007.

SARLET, Ingo Wolfgang. A eficácia dos direitos fundamentais. 3. ed. Porto Alegre: Livraria do Advogado, 2003.

SARMENTO, Daniel. Direitos fundamentais e relações privadas. 2. ed. Rio de Janeiro: Lumen Juris, 2006.

SILVA, José Afonso da. Aplicabilidade das normas constitucionais. 3. ed. São Paulo: Malheiros, 1998. 
${ }^{1}$ LOTUFO, Renan. Da oportunidade da codificação civil e a constituição. In: SARLET, Ingo Wolfgang (Org.) O novo código civil e a constituição. 2. ed. Porto Alegre: Livraria do Advogado, 2006, p. 21.

2 AMARAL, Francisco. Direito civil: introdução. 3. ed. Rio de Janeiro: Renovar, 2000, p. 151-153.

${ }^{3}$ Vale destacar que a Constituição de 1934, em seu artigo 113, já determinava que o direito de propriedade não poderá ser exercido contra o interesse social e coletivo. Todavia, a Constituição de 1937 não proibia que o direito de propriedade fosse exercido contrariamente aos interesses sociais e coletivos. A Constituição de 1967 e a Emenda Constitucional de 1969 foram as primeiras Cartas que utilizaram o termo "função social da propriedade", conforme art. 157 da Constituição de 1967 e artigo 160 da EC de 1969.

${ }^{4}$ TEPEDINO, Gustavo. O código civil, os chamados microssistemas e a constituição: premissas para uma reforma legislativa. In: TEPEDINO, Gustavo (Org.) Problemas de direito civil. Rio de Janeiro: Renovar, 2000, p. 3.

${ }^{5}$ MELLO, Cleyson de Moraes. Código civil interpretado. Rio de Janeiro: Freitas Bastos, 2007, p. XXIII.

${ }^{6}$ TEPEDINO, Gustavo. Normas constitucionais e direito civil na construção unitária do ordenamento. In: SOUZA NETO; Cláudio Pereira de; SARMENTO, Daniel. (Orgs.) A constitucionalização do direito: fundamentos teóricos e aplicações específicas. Rio de Janeiro. Lumen Juris, Renovar. 2007, p. 309.

${ }^{7}$ SARMENTO, Daniel. Direitos fundamentais e relações privadas. 2. ed. Rio de Janeiro: Lumen Juris, 2006, p. 124.

${ }^{8}$ TEPEDINO, Gustavo. Normas constitucionais e direito civil na construção unitária do ordenamento. In: SOUZA NETO; Cláudio Pereira de; SARMENTO, Daniel. (Orgs.) A constitucionalização do direito: fundamentos teóricos e aplicações específicas. Rio de Janeiro. Lumen Juris, Renovar. 2007, p. 318.

${ }^{9}$ MELLO, Cleyson de Moraes. Hermenêutica e direito. Rio de Janeiro: Freitas Bastos, 2006.

${ }^{10}$ SARLET, Ingo Wolfgang. A eficácia dos direitos fundamentais. 3. ed. Porto Alegre: Livraria do Advogado, 2003, p. 31.

${ }^{11}$ MARTÍNEZ, Gregorio Peces-Barba. Lecciones de derechos fundamentales. Madrid: Dykinson, 2004, p. 31.

${ }^{12} \mathrm{O}$ artigo $5^{\circ}$ apesar de exaustivo, não apresenta cunho taxativo.

${ }^{13}$ SARLET. Op. cit., p. 246.

${ }^{14}$ SARLET. Op. cit., p. 79.

${ }^{15}$ Ibid., p. 33-34.

${ }^{16}$ PEREZ LUÑO, Antonio-Enrique. Los derechos fundamentales. 8. ed. Madrid: Tecnos, 2004, p. 46.

${ }^{17}$ SARLET. Op. cit., p. 53.

${ }^{18}$ SILVA, José Afonso da. Aplicabilidade das normas constitucionais. 3. ed. São Paulo: Malheiros, 1998.

${ }^{19}$ Ibid., p. 103-104.

${ }^{20}$ DINIZ, Maria Helena. Norma constitucional e seus efeitos. 6. ed. São Paulo: Saraiva, 2003.

${ }^{21}$ BARROSO, Luís Roberto. O direito constitucional e a efetividade de suas normas. 5. ed. Rio de Janeiro: Renovar, 2001, p. 94.

${ }^{22}$ SARLET. Op. cit., p. 237-238.

${ }^{23}$ Ibid., p. 238.

${ }^{24}$ Ibid., p. 258.

${ }^{25}$ NOVAIS, Jorge Reis. Direitos fundamentais: trunfos contra a maioria. Coimbra: Coimbra Editora, 2006, p. 71-72.

${ }^{26}$ NOVAIS. Op. cit., p. 78.

${ }^{27}$ Ibid., p. 78.

${ }^{28}$ TEPEDINO, Gustavo. Normas constitucionais e direito civil na construção unitária do ordenamento. In: SOUZA NETO, Cláudio Pereira de; SARMENTO, Daniel. A constitucionalização do direito: fundamentos teóricos e aplicações específicas, Rio de Janeiro: Lumen Juris, 2007, p. 310-311. 
Artigo recebido em 07 de julho de 2016 e aceito em 15 de dezembro de 2016 